\title{
Patient-Centredness, Job Satisfaction and Psychological Distress: a Brief Survey Comparing Oncology Nurses and Doctors
}

\author{
Caryn Mei Hsien Chan ${ }^{1 *}$, Wan Azman Wan Ahmad ${ }^{2}$, Mastura MD Yusof ${ }^{3}$, Gwo \\ Fuang $\mathrm{Ho}^{3}$, Edward Krupat ${ }^{4}$
}

\begin{abstract}
Background: We aimed to explore whether levels of patient-centredness, job satisfaction and psychological distress varied between oncology nurses and doctors. Materials and Methods: In a cross-sectional study using self-administered questionnaires, a total of 24 nurses and 43 doctors were assessed for patient-centredness, psychological distress, and job satisfaction using the Patient-Practitioner Orientation Scale, Hospital Anxiety and Depression Scale, and Job Satisfaction Scale. Data were analysed using descriptive statistics, independent samples t-test and MANCOVA, with $\mathbf{p}<\mathbf{0 . 0 5}$ considered significant. Results: Overall response rate was $\mathbf{9 5 . 6 \%}$ $(\mathbf{4 3 / 4 5 )}$ for physicians and $85.7 \%(24 / 28)$ for nurses. Even after adjusting for known covariates, our principal finding was that doctors reported greater psychological distress compared to nurses $(p=0.009)$. Doctors also reported lower job satisfaction compared to nurses $(p=0.017)$, despite higher levels of patient-centredness found in nurses $(p=0.001)$. Findings may be explained in part by differences in job characteristics and demands. Conclusions: Mental health is an important concern not just in cancer patients but among healthcare professionals in oncology.
\end{abstract}

Keywords: Doctors - nurses - patient-centredness - psychological distress - job satisfaction

Asian Pac J Cancer Prev, 16 (16), 6895-6898

\section{Introduction}

The medical profession is undergoing increasing changes in practice (Wang et al., 2011). In the current climate of patient-centred care, ongoing debate on clinician dominance (Bensing et al., 2013) adds to the challenges of working within an inherently demanding specialty such as oncology (Shanafelt and Dyrbye, 2012; Eelen et al., 2014). While there is now significant literature on patient-centredness and its resultant outcomes in patients with cancer (Krupat et al., 2000; Bensing et al., 2013), few studies have undertaken to examine how patientcentredness impacts job satisfaction and psychological distress in both oncology doctors and nurses.

In Malaysia, the prevailing patient preference and culture is mostly paternalistic or doctor-centred, particularly among older patients, although this trend is changing among urban and younger cancer patients who may prefer patient-centred care (Chan and Wan Azman, 2012). This, in addition to the rigours of clinical work, teaching and research typical in the oncology clinic such as in the current study setting, may contribute in no small part to the job satisfaction and psychological distress of doctors and nurses alike (Wada et al., 2009; Pratt, 2010;
Fridneret al., 2012; Fu et al, 2013).

The present study was thus conducted to examine job satisfaction and psychological distress in doctors and nurses in the context of these changes in medical care. Specifically, the objective of this study was to compare the levels of patient-centredness, job satisfaction and psychological distress between doctors and nurses in a cancer clinic. We hypothesized that patient-centredness would be associated with higher job satisfaction and lower psychological distress in doctors and nurses.

\section{Materials and Methods}

We used a cross-sectional design. All doctors and nurses from a single oncology clinic of an academic medical centre were directly solicited to anonymously complete a set of questionnaires between January 2012 to June 2014. The self-administered questionnaires were numbered to allow tracking of returns. Institutional ethics approval was obtained for this study.

\section{Patient Practitioner Orientation Scale (PPOS)}

The Patient Practitioner Orientation Scale (Krupat et al., 2000) was designed to measure attitudes of patients 
and doctors towards patient-centred care. It comprises of 20 items on 6-point Likert scales on responses that span different levels of agreement or disagreement. Higher scores indicate patient-centredness, whereas lower scores denote doctor- or disease-centredness. The PPOS was used in this study to measure levels of patient-centredness in doctors and nurses.

\section{Job satisfaction Scale (JSS)}

Five domains of job satisfaction were examined (Bovier and Perneger, 2003). These comprised of 17 items measuring patient care, burden, income prestige, personal rewards, professional relations and general items on a scale of 0 to 7 , where 0 indicates low satisfaction and 7 indicates the highest possible level of satisfaction.

\section{Hospital Anxiety and Depression Scale (HADS)}

Psychological distress was measured using the 14 item Hospital Anxiety and Depression Scale or HADS, a widely utilised screening tool which comprises of two subscales examining anxiety and depression (Zigmond and Snaith, 1983). A cut-off score of 8 over 21 for each subscale was used. The total score for the entire scale or both subscales ranges from 0 to 42 . The scale has been used and extensively validated in patients, the general population and in health care providers alike.

\section{Statistical analyses}

Descriptive statistics were analysed. A multivariate analysis of covariance (MANCOVA) was performed, with patient-centredness as the independent continuous variable, with job satisfaction and psychological distress as the dependent variables. Profession (doctor or nurse), age, ethnicity and marital status was adjusted for. A p $<0.05$ level of significance was adopted. Results were analysed using SPSS version 21.0.

\section{Results}

Overall response rate was $95.6 \%$ (43/45) for doctors and $85.7 \%$ (24/28) for nurses. Questionnaires which were incomplete (more than $15 \%$ of items missing) were excluded from the analysis. The mean respondent age was 33 years for doctors (age range 29-46) and 38 years for nurses (range 26-53). The majority of participants were female, married and had received their undergraduate training locally. Table 1 displays the other characteristics of the study participants. There were no significant differences between doctors and nurses in terms of demographic characteristics.

Table 2 shows the means for the PPOS, JSS and HADS. Using independent t-tests, the means between doctors and nurses for patient-centredness, job satisfaction and psychological distress were found to be significantly different $(\mathrm{p}<0.001)$.

The majority of doctors had higher PPOS scores which denoted higher levels of patient-centredness. Doctors were on average more patient-centred than nurses, with a mean PPOS of 4.01 compared to the 3.38 mean PPOS of nurses who appeared to be more doctor-centred $(\mathrm{p}=0.001)$.

Doctor job satisfaction based on the JSS was an average of 4.9 out of a maximum score of 7 , whereas nurses had a mean satisfaction score of 5.3 out of 7. Job satisfaction was found to be significantly higher among nurses compared to doctors $(\mathrm{p}=0.017)$.

Doctor HADS scores were significantly higher than nurses, with total scores of 12.88 and 7.75 respectively. When broken down into the anxiety and depression subscales, doctors were still found to have significantly higher anxiety and depression subscale scores than did nurses $(\mathrm{p}=0.009)$ (Table 2).

Multivariate (MANOVA) analyses showed that doctors had higher levels of patient-centredness than nurses $(\mathrm{F}(1$, $59)=11.58 ; \mathrm{p}<0.001 ;$ partial eta squared $=0.16)$. These were confirmed across both dependent variables. When age, gender and marital status were added as covariates these effects became even stronger.

Multivariate (MANCOVA) analyses showed that even after adjusting for age, gender and marital status, there was

Table 1. Sociodemographic Characteristics of Oncology Physicians and Nurses $(\mathrm{N}=67)$

\begin{tabular}{|c|c|c|c|}
\hline Demographics & $\begin{array}{l}\text { Doctors } \\
(n=43)\end{array}$ & $\begin{array}{l}\text { Nurses } \\
(\mathrm{n}=24)\end{array}$ & $\begin{array}{l}\text { Total } \\
\mathrm{n}(\%)\end{array}$ \\
\hline Mean age $\pm S D$ & $33.17 \pm 3.67$ & $37.96 \pm 8.26$ & $34.89 \pm 6.14$ \\
\hline range (years) & $29-46$ & 26-53 & $26-53$ \\
\hline \multicolumn{4}{|l|}{ Age } \\
\hline $25-35$ & 31 & 9 & 40 \\
\hline $36-46$ & 10 & 11 & 21 \\
\hline $47-55$ & 0 & 3 & 3 \\
\hline Unknown & 2 & 1 & 3 \\
\hline \multicolumn{4}{|l|}{ Gender } \\
\hline Male & $15(34.9)$ & $0(100)$ & $15(22.4)$ \\
\hline Female & $28(65.1)$ & $24(100)$ & $52(77.6)$ \\
\hline \multicolumn{4}{|c|}{ Ethnic background } \\
\hline Malay & 17 & 19 & $36(53.7)$ \\
\hline Chinese & 16 & 3 & $19(28.4)$ \\
\hline Indian & 8 & 2 & $10(14.9)$ \\
\hline Others & 2 & 0 & $2(3.0)$ \\
\hline \multicolumn{4}{|l|}{ Religion } \\
\hline Islam & 17 & 20 & $27(55.2)$ \\
\hline Buddhism & 11 & 1 & $12(17.9)$ \\
\hline Hindu & 7 & 2 & $9(13.4)$ \\
\hline Christianity & 6 & 1 & $7(10.4)$ \\
\hline Others & 2 & 0 & $2(3.0)$ \\
\hline \multicolumn{4}{|l|}{ Marital status } \\
\hline Single & 17 & 5 & $22(32.8)$ \\
\hline Married & 25 & 17 & $42(58.2)$ \\
\hline Unknown & 1 & 2 & $3(4.5)$ \\
\hline \multicolumn{4}{|l|}{ Training } \\
\hline Local & 30 & 24 & $54(80.6)$ \\
\hline Abroad & 7 & 0 & $7(10.4)$ \\
\hline Both & 6 & 0 & $6(9.0)$ \\
\hline
\end{tabular}

Table 2. Means and Standard Error for Physician and Nurse Scores

\begin{tabular}{lcclll}
\hline Groups & \multicolumn{2}{c}{ Physicians $(\mathrm{n}=43)$} & & \multicolumn{2}{c}{ Nurses $(\mathrm{n}=24)$} \\
\cline { 2 - 3 } \cline { 6 - 6 } Variables & Mean & SE & & Mean & SE \\
\hline PPOS & 4.01 & 0.09 & & 3.38 & 0.11 \\
Job satisfaction & 4.9 & 0.09 & & 5.33 & 0.11 \\
HADS Anxiety & 7.35 & 0.52 & & 5.08 & 0.61 \\
HADS Depression & 5.53 & 0.5 & & 2.67 & 0.53 \\
HADS total & 12.88 & 0.94 & & 7.75 & 1.07 \\
\hline
\end{tabular}


Patient-Centredness, Job Satisfaction and Psychological Distress: a Brief Survey Comparing Oncology Nurses and Doctors Table 3. MANCOVA results in Comparison of Dependent Variables between Physicians and Nurses

\begin{tabular}{lcccccc}
\hline Dependent variable & Sum of Squares & df & Mean Square & F & Sig. & Partial Eta Squared \\
\hline PPOS & 3.691 & 1 & 3.691 & 11.576 & 0.001 & 0.164 \\
Job satisfaction & 2.167 & 1 & 2.167 & 6.039 & 0.017 & 0.093 \\
HADS Anxiety & 50.401 & 1 & 50.401 & 4.553 & 0.037 & 0.072 \\
HADS Depression & 75.804 & 1 & 75.804 & 8.122 & 0.006 & 0.121 \\
HADS total & 249.828 & 1 & 249.828 & 7.201 & 0.009 & 0.109 \\
\hline
\end{tabular}

a significant difference between doctors and nurses (Wilks' lambda $=0.703, \mathrm{~F}(4,56)=5.916, \mathrm{p}<0.001$, partial eta squared $=0.297$. None of the covariates were significant.

Further follow-up tests were conducted to determine how the dependent variables differed for the independent variable. Tests of between-subject effect was examined in Table 5.We can see from this table that being a doctor or nurse has an effect on patient-centredness $(\mathrm{F}(1,59)=11.58 ; \mathrm{p}<0.001 ;$ partial eta squared $=0.16)$, job satisfaction $(\mathrm{F}(1,59)=6.309 ; \mathrm{p}<0.017$; partial eta squared $=0.09)$, anxiety $(\mathrm{F}(1,59)=4.55 ; \mathrm{p}<0.037$; partial eta squared $=0.07)$, depression $(\mathrm{F}(1,59)=8.12 ; \mathrm{p}<0.006$; partial eta squared $=0.12$ ), overall psychological distress $(F(1,59)=7.20 ; \mathrm{p}<0.009$; partial eta squared $=0.11)$.

\section{Discussion}

There is limited regional data in this area, as the bulk of past studies have focused mostly on Caucasian samples (Dowell et al., 2001; Sveinsdottir et al., 2006; Leung et al., 2014). Most researchers examining patient-centredness have traditionally focused on patients themselves and the resultant outcomes of patient-centred care. This study is novel in that it links patient-centredness to job satisfaction and psychological distress in doctors and nurses.

Our results show that there are clear differences in the levels of patient-centredness between doctors and nurses. Oncology nurses were surprisingly less patient-centred than were the doctors in this sample. This is interesting to note as nurses who are supposed to be more familiar with the concept of patient-centredness appeared to be doctorcentred compared to the doctors in our sample. It would be interesting to see whether the levels of patient centredness in nurses would be similar to their counterparts in other specialties.

The finding that anxiety and depressive symptoms are common among oncologists in Malaysia despite a high level of patient-centredness is similar to a study by Gong, Han et al. (2014) which found that psychological distress in Chinese physicians was attributable to doctor-patient relationship issues.

Oncology doctors were more anxious and depressed, and reported lower job satisfaction than nurses. This may be explained in part by differences in job characteristics and demands. One reason for this may be attributable to the fact that the majority of respondents in this sample were master of oncology trainees and therefore under stress due to the rigours of postgraduate specialty training and examinations. This is in line with findings by Mache et al. (2011) and Ogundipe et al. (2014) of high burnout rates among doctors undergoing residency training.

Oncologists have been found to be more patient- centred than physicians from at least three other medical specialties (Chan et al., 2012). Previous studies have also shown that oncologists are more likely to be stressed than doctors in other specialties (Shanafelt et al., 2012). Our findings are similar to a study by Dowell (2011) which found that doctors are generally satisfied with their jobs, but with levels of psychological morbidity that has been reported previously as a cause for concern.

In our study, nurses were found to have lower levels of psychological distress and higher job satisfaction compared to doctors in the same oncology clinic. Most of the nurses had been working for longer than the oncologists, and were older (mean age of 38 years as opposed to 33 years). It has been shown that younger clinicians (Grob et al., 2014) and those who devote the highest amount of time to clinic are at highest risk for burnout and lower job satisfaction (Shanafelt, 2012).

Our findings offer insight into levels of patientcentredness, satisfaction and psychological distress in an oncology clinic. Although this study only focused on oncology doctors and nurses, psychological distress and job satisfaction is not unique to any particular specialty or healthcare role. Future lines of enquiry could potentially focus on the transition between being an oncology trainee or nurse and becoming an oncologist or nurse specialist.

This study is not without its limitations. This was a single center study, and our sample of oncology doctors included trainees. The small sample size is another limitation, although the current sample is a good representative of the current population of oncology professionals in the country since trainees rotate to three main oncology centers in the country. Our centre is currently the sole clinical training program producing new oncologists in the country, and therefore represents oncology trainees and clinical oncologists in Malaysia.

Providing care can cause distress, but receiving training in communication skills may be effective for oncology doctors and nurses to assimilate patient-centred care. As the prevalence of psychological distress in the oncology clinic is high, early detection through selfadministered questionnaire screening is recommended to improve distress and job satisfaction among oncology staff, which may in turn improve the quality of patientphysician relationships in the cancer setting.

\section{Acknowledgements}

We would like to thank all the physicians and nurses who participated in this research. This study was supported by University of Malaya's High Impact Research (HIR) breast cancer grant UM.C/HIR/MOHE/06/H-500100-A000020-000001. 


\section{References}

Bensing JM, Van den Brink-Muinen A, Boerma W, Van Dulmen S (2013). The manifestation of job satisfaction in doctorpatient communication; a ten-country European study. Int $J$ Pat Cent Med, 3, 44-52.

Bovier PA, Perneger TV.(2003). Predictors of work satisfaction among physicians. Eur J Public Health, 13, 299-05.

Chan CMH, Azman WA. (2012). Attitudes and role orientation on doctor-patient fit and patient satisfaction in cancer care. Sing Med J, 53, 52-6.

Dowell AC, Westcott T, McLeod DK, Hamilton S (2001). A survey of job satisfaction, sources of stress and psychological symptoms among New Zealand health professionals. $N Z$ Med J, 114, 540-3.

Eelen S, Bauwens S, Baillon C, et al (2014). The prevalence of burnout among oncology professionals: oncologists are at risk of developing burnout. Psycho Oncol, 12, 1415-22.

Fridner A, Belkic K, Marinif M, Gustafsson Sendena SGK (2012). Why don't academic physicians seek needed professional help for psychological distress. Swiss Med Wkly, 142, 13626.

Fu J, Sun W, Wang Y, Yang X, Wang L (2013). Improving job satisfaction of Chinese doctors: the positive effects of perceived organizational support and psychological capital. Public Health, 127, 946-51.

Gong Y, Han T, Chen W, et al (2014). Prevalence of anxiety and depressive symptoms and related risk factors among physicians in china: a cross-sectional study. PLOS ONE, 9, 103242.

Grob SE, Ernstmann N, Jung J, et al. (2014). Can a stressed oncologist be good in a consultation? A qualitative study on the oncologists' perception. Eur J Cancer Care, 23, 594-606.

Grob SE, Ernstmann N, Jung J, et al (2014). Can a stressed oncologist be good in a consultation? A qualitative study on the oncologists' perception. Eur J Cancer Care, 23, 594-606.

Guveli H, Anuk D, Serap O, et al (2015). Oncology staff: burnout, job satisfaction and coping with stress. Psycho Oncol,

Jacobsen PB, Holland JC, Steensma DP. (2012). Caring for the whole patient: the science of psychosocial care. J Clin Oncol, 30, 1151-3.

Krupat E, Yeager CM, Putnam S. (2000). Patient role orientations, doctor-patient fit, and visit satisfaction. Psychol Health, 15, 707-19.

Leung J, Rioesco P, Munro P. (2014). Stress, satisfaction and burnout amongst Australian and New Zealand radiation oncologists. J Med Imag Rad Oncol, 59, 115-24.

Mache S, Schoffel N, Kusma B, Vitzthum K, Klapp BF, Groneberg DA. (2011). Cancer care and residents' working hours in oncology and hematology departments: an observational real-time study in German hospitals. Jap J Clin Oncol, 41, 81-6.

Pratt WR (2010). Physician career satisfaction: examining perspectives of the working environment. Hosp Topics, 88, 43-52.

Renzi C, Di Pietro C, Tabolli S (2012). Psychiatric morbidity and emotional exhaustion among hospital physicians and nurses: association with perceived job-related factors. Arch Environ Occup Health, 67, 117-23.

Shanafelt T, Dyrbye L (2012). Oncologist burnout: causes, consequences and responses. J Clin Oncol, 20, 1235-41.

Shanafelt TD, Boone S, Tan L, et al (2012). Burnout and satisfaction with work-life balance among US physicians relative to the general US population. Arch Intern Med.

Solberg IB, Ro KI, Aasland O, et al (2012). The impact of change in a doctor's job position: a five-year cohort study of job satisfaction among Norwegian doctors. BMC Health Serv Res, 12, 41.

Sveinsdottir H, Biering P, Ramel A (2006). Occupational stress, job satisfaction, and working environment among Icelandic nurses: a cross-sectional questionnaire survey. Int J Nurs Stud, 43, 875-89.

Wada K, Arimatsu M, Higashi T, et al (2009). Physician job satisfaction and working conditions in Japan. J Occup Health, 51, 261-6.

Zigmond AS, Snaith RP (1983). The hospital anxiety and depression scale. Acta Psychiatr Scand, 67, 361-70. 